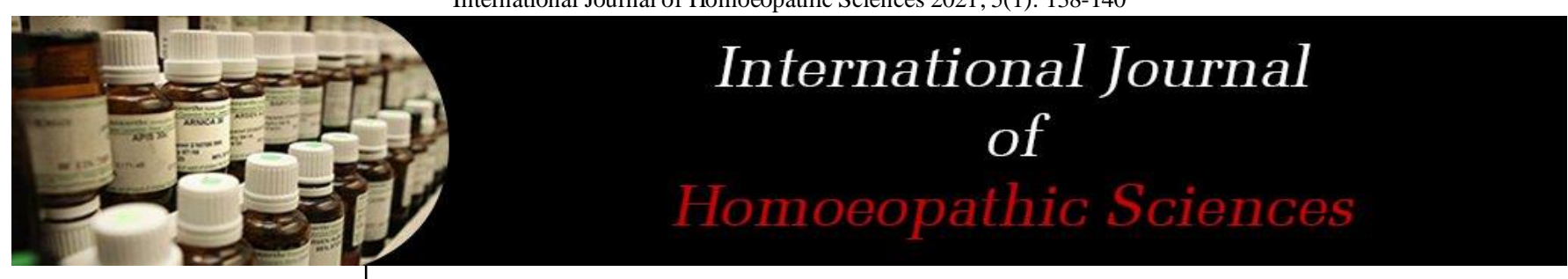

E-ISSN: 2616-4493 P-ISSN: 2616-4485 www.homoeopathicjournal.com IJHS 2021; 5(1): 138-140 Received: $29-10-2020$ Accepted: 07-12-2020

Dr. J Lordson Jebarathinam Associate Professor,

Department of Case-Taking \& Repertory, Yenepoya

Homoeopathic Medical College \& Hospital, Deemed to be University, Naringana, Deralakatte, Mangalore, Karnataka, India
Corresponding Author: Dr. J Lordson Jebarathinam Associate Professor, Department of Case-Taking \& Repertory, Yenepoya Homoeopathic Medical College \& Hospital, Deemed to be University, Naringana, Deralakatte, Mangalore, Karnataka, India

\section{Overcoming the difficulties in treatment of hypertension clinically using synthesis (modern) repertory}

\section{Dr. J Lordson Jebarathinam}

DOI: https://doi.org/10.33545/26164485.2021.v5.i1c.304

\begin{abstract}
In this cutting-edge period Hypertension is a sickness which influences nearly every one of the middle and old age groups. The vast majority of the individuals being impervious to the conventional method of treatment, new homeopathic treatment strategies dependent on present day (modern) repertories having clinical rubrics can be easily adapted to adequately prevent or delay the progression of complication in Hypertension.
\end{abstract}

Keywords: Blood pressure, homoeopathic management, modern homoeopathic practice, synthesis repertory, clinical rubrics

\section{Introduction}

Hypertension stays a significant modifiable danger factor for cardiovascular sickness regardless of significant advances in our comprehension of its pathophysiology and the accessibility of powerful therapy methodologies, there is proof that the illness is just deteriorating. Hypertension being an asymptomatic and common condition, can bring up deadly complications whenever left untreated ${ }^{[3]}$. The "silent killer" as it is known, is gradually becoming a problem of enormous proportions in the developing world ${ }^{[2]}$. It is many a times silent or gives only mental symptom like irritability in trifle, intolerance to opposition, easy fatigue or palpitation, or headache for which it is neglected most and one day it shows its grievous consequence in the form of cerebral hemorrhage or thrombosis. So measurement of blood pressure is to be done in every month in healthy individual after 40 years of age. Pertaining to the present era and the advancement with modern repertories, we will be able effectively control the Blood pressure $\&$ also prevent/delay the progression with available clinical symptoms ${ }^{[6]}$.

\section{Incidence}

The predominance of hypertension increases with age. Hypertension is uncontrolled in practically $50 \%$ of the population, and of those with uncontrolled hypertension, about $36 \%$ are not aware of the finding. Indeed, even in patients in whom hypertension is analyzed and treated, control is accomplished in just $60 \%$. Cardiovascular, mortality is seen in both systolic and diastolic blood pressures rise, yet in people over age 50 years, the systolic pressure and heart rate are better indicators of Hypertension ${ }^{[7]}$

\section{Definition of blood pressure}

Blood pressure is a continuous variable, with no absolute dividing line between normal and abnormal values and risks of various adverse outcomes rise with it. A blood pressure of less than $120 / 80 \mathrm{mmHg}$ is defined as "normal" in adults. Hypertension is usually diagnosed on finding blood pressure of $140 / 90 \mathrm{mmHg}$ or above, measured on both arms on three occasions over a few weeks. Blood pressure ranging $120 / 80 \mathrm{mmHg}$ to $140 / 90 \mathrm{mmHg}$ as "prehypertension". Prehypertension is not a disease category. Rather, it is a designation chosen to identify individuals at high risk of developing hypertension (JNC VII) ${ }^{[8,12]}$ $\dagger$ When systolic and diastolic blood pressure falls into different categories, the higher category should be selected to classify the individual's blood pressure status.

tBased on the average of two or more readings taken at two or more visits after an initial screening. 


\section{Clinical features}

Most people with primary hypertension don't have any obvious symptoms at all, in under $10 \%$ of cases, it is brought about by such factors as diabetes, kidney illness, urinary tract infections, anemia, or the nearness of abdominal masses including: Obstructive rest apnea, Kidney issues, Adrenal organ tumors, Thyroid issues Illicit medications, for example, cocaine and amphetamines. However here are a few of the more common symptoms of hypertension to look out for: chronic headaches, Dizziness or Vertigo, Blurry or double vision Drowsiness, Nausea, Shortness of breath, palpitations, Fatigue - general tiredness, flushed face, Nosebleeds, a strong need to urinate often (especially during the night), Tinnitus (a ringing or buzzing in the ears) ${ }^{[11,8]}$.

Malignant Hypertension: About $1 \%$ of hypertensives develop the malignant phase. It is a health related crisis, requiring immediate treatment.

\section{Management of hypertension}

The essential objective of treating of hypertension is effective control of BP to prevent, or delay the progression of complications and accordingly lowering the overall risk of an individual without affecting the quality of life ${ }^{[8,11]}$.

\section{Management Strategy}

Table 1: Having assessed the patient and determined the overall risk profile, the management of hypertension should proceed as follows ${ }^{[12]}$.

\begin{tabular}{|c|c|}
\hline Low risk patients & lifestyle modifications and monitor BP for a period of 3-6 months \\
\hline Medium risk patients & lifestyle modification and BP remain above $140 / 90 \mathrm{~mm}>6$ months of $\mathrm{Hg}$ then initiate drug therapy \\
\hline High risk patients & initiate immediate drug treatment \\
\hline
\end{tabular}

\section{Homoeopathic Approach to Hypertension}

1. Case taking $(\$ 83-\S 104)^{[4]}$.

2. Analysis of the case ${ }^{[4]}$.

3. Totality of the case ${ }^{[4]}$.

4. Repertorial Analysis ${ }^{[4]}$.

5. Selection of the remedy ${ }^{[4]}$.

\section{Difficulties in treatment}

One Sided Expression: One most common difficulty a practitioner could encounter in treating hypertension would be the paucity of symptoms or the absence of peculiar, queer $\&$ rare symptoms. Truly one sided cases are very difficult to treat and are very often incurable. Dr. Kent has emphasized this point saying "all curable diseases make themselves known to the physician by signs and symptoms. You must not expect to cure when the peculiar symptoms are absent" [5]. However, a complete and thorough case taking is warranted in such cases and a remedy is to be selected based on the few symptoms available.

Patients under Old school of Treatment: Majority of the patients with essential hypertension approach the homoeopathic physician after undergoing some form of allopathic treatment. Cases which have undergone prolonged treatment for hypertension and other illnesses are very difficult to treat, as the original symptomatology is often not available ${ }^{[10]}$. Hahnemann says about such cases in general "They often require a much longer time for their recovery, often indeed are they incurable" $(\$ 149){ }^{[4]}$. One should not discontinue the allopathic treatment abruptly; sudden withdrawal may do more harm than good. Dr. Stuart Close says that the sphere of homoeopathy is in "affections of the living organism where perceptible symptoms exist, similar to that produced by pathogenetic means, in organisms having the integrity of tissues and reactive powers of recovery, the exciting causes of the affections and the obstacles to recovery having been removed" ${ }^{[1]}$. The statement is very much true in cases of hypertension.

\section{Managing hypertension using modern repertory}

Homoeopathy is an art well the Repertory is the artistic composition of the results of scientific proving of Medicine [1]. The sole purpose of Repertory is to facilitate the search of most similar remedy at the most comprehensive way ${ }^{[7]}$. Hypertension having an idiopathic etiology, most of the times as a homoeopathic physician we don't usually get much of the symptoms or the portrait of the disease to frame a constitutional totality. And we are left with few clinical symptoms, common causative factor along with their concomitants to consider ${ }^{[6,7]}$. If not, the patient comes after over drugging in allopathic treatment with combined malady of renal or cardiac origin. The modern repertory like synthesis, Murphy come into play at this occasion which are designed accordingly to handle the clinical and adverse pathologies at ease \& reduce further complications.

\section{Case processing}

According to modern repertories initially we should analyze a case and one must perceive what has to be cured in the case based on ${ }^{[6]}$.

I. Aetiology

II. Underlying area of affection and extent

III. Relating the condition clinically

IV. Prognosis of case.

The case analysis has to be based on what is most life threatening to the patient. Next the ailment factor to the case and most severe symptoms along with the general concomitant and finally the clinical rubrics has to be taken. There is no fixed hierarchy in case analysis. These rubrics can be taken in the repertory to differentiate choice the remedies and Materia Medica should be referred for final similimum ${ }^{[9]}$. 
Table 2: Few useful rubrics of hypertension in Shroyens F synthesis ${ }^{[9,13]}$ (few similar rubrics are also found in Murphy Repertory)

\begin{tabular}{|c|cll|}
\hline Clinical Aspects & & \multicolumn{1}{c|}{ Rubrics } \\
\hline Clinical /General Rubrics & $\checkmark$ & Generals - Hypertension \\
\hline \multirow{3}{*}{ Essential Hypertension } & $\checkmark$ & Generalities - Essential Hypertension \\
& $\checkmark$ & Generalities - Hypertension - Diastolic Pressure Only. \\
& $\checkmark$ & Generalities - Hypertension - Systolic Pressure Only: \\
\hline \multirow{2}{*}{ Acute Hypertension } & $\checkmark$ & Generals - Hypertension - Sudden: \\
& $\checkmark$ & Generals - Hypertension - Excessive: \\
\hline \multirow{2}{*}{ Renal Hypertension } & $\checkmark$ & Kidneys - Hypertension: \\
& $\checkmark$ & Kidneys - Complaints of Kidneys - Accompanied By - Hypertension: Kidneys - \\
& & Nephrosis - Accompanied By - Hypertension: \\
& $\checkmark$ & Generals - Hypertension - Dialysis; From: \\
& $\checkmark$ & Generals - Hypertension - Accompanied By - Urine; Albuminous: \\
\hline Cardiac Hypertension/Hypertensive Heart & $\checkmark$ & Chest - Dilatation of Heart - Accompanied By - Hypertension: \\
& $\checkmark$ & Chest - Hypertrophy - Heart; of - Accompanied By - Hypertension: \\
\hline \multirow{2}{*}{ Disease } & $\checkmark$ & Generals - Hypertension - Pulmonary: \\
& $\checkmark$ & Generals - Hypertension - Lung Complaints; After: \\
\hline \multirow{2}{*}{ Cerebral Hypertension } & $\checkmark$ & Generals - Apoplexy - Accompanied By - Hypertension: \\
& $\checkmark$ & Generals - Hypertension - Nervous Mechanism; Due To Disturbed: \\
\hline Diabetic Hypertension & $\checkmark$ & Generals - Diabetes Mellitus - Accompanied By - Hypertension: \\
& $\checkmark$ & Generals - Hypertension - Accompanied By - Head; Pain In: \\
& $\checkmark$ & Generals - Hypertension - Accompanied By - Head; Pain In - Morning: \\
& $\checkmark$ & Generals - Hypertension - Accompanied By - Face; Red Discoloration of \\
& $\checkmark$ & Mind - Sadness - Hypertension; With: Extremities - Cold - Hands - Hypertension, \\
& & During Crisis of: \\
& $\checkmark$ & Dreams - Disease - Hypertension and A Very High Cholesterol Level, Being Told \\
& & That An Old Man Has Severe: \\
\hline \multirow{2}{*}{ Hypertension Related Accompaiments } & &
\end{tabular}

\section{Conclusion}

Thus, by proper case analyzing and making use of the available rubrics in modern repertories Homoeopathy can effectively and promptly overcome the difficulties in treating hypertension by accurately preventing, or delay the progression of complications and reduce the overall risk of an individual without affecting the quality of life.

\section{References}

1. Boericke WM. A compend of the principles of Homoeopathy. Reprint Edition, B. Jain Publishers Pvt. Ltd, New Delhi, India. 1990, 26, 50.

2. Castro Bendict D. Logic of Repertories. Reprint Edition New Delhi, India. B.Jain Publishers Pvt. Ltd 1995, 57.

3. Close Stuart. The Genius of Homoeopathy. Reprint Edition New Delhi, India. B.Jain Publishers Pvt. Ltd 1995, 42, 153.

4. Guyton Arthur C, Hall John E. Textbook of Medical Physiology. 10 ${ }^{\text {th }}$ Edition. Asia Pvt Ltd 2001, 199, 205.

5. Hahnemann Samuel. Organon of Medicine. Reprint Edition. Indian Books \& Periodicals Publishers 2001, 92, 93, 157.

6. Kent James Tyler. Lectures on Homoeopathic Philosophy. Reprint Edition. New Delhi, India. B.Jain Publishers Pvt. Ltd 1999, 162.

7. Krishnadas KV. Textbook of Medicine. $5^{\text {th }}$ Edition. Jaypee Brothers Medical Publishers (P) Ltd. 2008, 829, 834.

8. Kumar Parveen, Clarke Michael. Clinical Medicine" $5^{\text {th }}$ Edition. W B Saunders Elsevier Science Limited 2003, 819.

9. Maxim Papadiks A, Stephen Macphee J. Current Medical Diagnosis \& Treatment. $5^{\text {th }}$ Edition. New York. Mcgraw Hill Education.

10. Murphy Robin ND. Homoeopathic Medical Repertory. $3^{\text {rd }}$ Revised Edition. New Delhi, India. B. Jain Publishers Pvt. Ltd 2011, 34, 35.

11. Roy Ravi. Need for New and Reliable Repertory. The practical Repertory Online, The homoeopathic Heritage 2008;33:31.

12. Schepper Luc De. Hahnemann Revisited-A Textbook of Classical Homoeopathy For The Professional. Reprint Edition, B.Jain Publishers Pvt. Ltd, New Delhi, India. 2006, 407.

13. Schroyen's Frederik. Synthesis Repertorium Homoeopathicumsyntheticum9.1. (RADAR OPUS) New Delhi, India. B.Jain Publishers Pvt. Ltd 2016.

14. Adi GB. A complete review of principles and cure of homoeopathy.

15. Shah Siddharth N. API Textbook of Medicine. $8^{\text {th }}$ Edition. The Association of Physicians of India 2008;I:531.

16. Shashi Kant Tiwari. Essentials of Repertorization. $4^{\text {th }}$ Edition. New Delhi, India. B. Jain Publishers Pvt. Ltd.

17. Vithoulkas George. The Science of Homoeopathy. Reprint Edition. New Delhi, India. B.Jain Publishers Pvt. Ltd 1993;173:254.

18. Zandvoort Van Roger. The Complete Repertory. Reprint Edition, Institute for Research on Homoeopathic Information and Symptomatology 1998.

19. A Historical Look at Hypertension: Celebrating 100 Years with the Southern Medical Association, Southern Medical Journal 2006.

20. Adam Felman. Medical news today [Internet]. [cited November 13, 2019] (https://www.medicalnewstoday.com/articles/159283\#s ymptoms)

21. The Seventh Report of the Joint National Committee on Prevention, Detection, Evaluation, and Treatment of High Blood Pressure [Internet]. NIH Publication No. 03-5233. [Cited December 2003]. Available from (http://www.nhlbi.nih.gov/guidelines/hypertension/phy card.pdf)

22. http://www.similima.com 